\title{
The health burden of pollution: the impact of prenatal exposure to air pollutants
}

\author{
This article was published in the following Dove Press journal: \\ International Journal of COPD \\ 10 June 2015 \\ Number of times this article has been viewed
}

\author{
Sandra E Vieira \\ Pediatrics Department, Medical \\ School, University of São Paulo, \\ São Paulo, Brazil
}

Correspondence: Sandra E Vieira Pediatrics Department, Medical School, University of São Paulo, Av Dr Eneas de Carvalho Aguiar, 647, 05403-000 São Paulo, Brazil

Email sandra@hu.usp.br

\begin{abstract}
Exposure to atmospheric pollutants in both open and closed environments is a major cause of morbidity and mortality that may be both controlled and minimized. Despite growing evidence, several controversies and disagreements exist among the studies that have analyzed the effects of prenatal pollutant exposure. This review article aims to analyze primary scientific evidence of the effects of air pollution during pregnancy and the impact of these effects on the fetus, infant health, and in particular, the respiratory system. We performed a review of articles from the PubMed and Web of Science databases that were published in English within the past 5 years, particularly those related to birth cohorts that began in pregnancy with follow-up until the first years of life. The largest reported effects are associated with prenatal exposure to particulate matter, nitrogen dioxide, and tobacco smoke. The primary effects affect birth weight and other parameters of fetal biometry. There is strong evidence regarding the impact of pollutants on morbidity secondary to respiratory problems. Growing evidence links maternal smoking to childhood asthma and wheezing. The role of passive maternal smoking is less clear. Great heterogeneity exists among studies. There is a need for additional studies on birth cohorts to monitor the relationship between the exposure of pregnant women to pollutants and their children's progress during the first years of life.
\end{abstract}

Keywords: air pollutants, pregnancy, birth weight, lung disease, tobacco, fetal development

\section{Introduction}

The environmental changes promoted by humans as a result of changes in lifestyles, customs, and technologies have repercussions for both health and quality of life. Exposure to atmospheric pollutants generated in both open and closed environments is a major cause of morbidity and mortality that may be both controlled and minimized. ${ }^{1}$

According to the World Health Organization, approximately 3.7 million premature deaths worldwide were caused by environmental exposure to air pollutants in 2012, $20 \%$ were caused by respiratory diseases $(14 \%$ - obstructive pulmonary disease or chronic respiratory infections and $6 \%$ - lung cancer), and approximately $80 \%$ were caused by ischemic heart disease and stroke. ${ }^{1}$

Among children, more than half of premature deaths secondary to pneumonia appear to result from exposure to particulate matter (PM) inhaled within the home. Indoor pollution, particularly tobacco smoke (TS) and the pollution generated via the combustion of biomass and coal, accounted for approximately 4.3 million of premature deaths during the same year. ${ }^{1}$ In addition to its impact on mortality, pollution also impacts the productive life years of the population. Outdoor pollution is responsible for more than $3 \%$ of lost productive life years, according to a global study that assessed the impact exerted by risk factors for either death or disability due to illness, and is ranked among the top ten causes of disability and death worldwide in 2010. Exposure to cigarette 
smoke, including passive smoking, was characterized as the second leading cause of lost productivity in this study. ${ }^{2}$

More recent studies have analyzed the importance of exposure to air pollutants during intrauterine life and the possible repercussions of the said exposure at birth, during childhood, and during adulthood. Experimental animal studies have demonstrated the specific effects exerted by air pollutants, the findings of which have provided the theoretical basis for research in humans. ${ }^{3-5}$

Despite growing evidence, several controversies and disagreements exist among the studies analyzing the effects of prenatal pollutant exposure. ${ }^{6}$ These discordances result from different study designs, exposure measurement methods, exposure times, and population characteristics, as well as other possible biases. The most appropriate study design with which to assess the impact of prenatal exposure is a birth cohort that monitors exposure during pregnancy that also utilizes longitudinal follow-up to analyze the outcomes for the fetuses at birth and following birth. Several cohort studies have been conducted to further elucidate the relationship between prenatal exposure and health outcomes. ${ }^{6-8}$

This review article aims to analyze primary scientific evidence of the effects of air pollution during pregnancy and the impact of these effects on the fetus, infant health, and in particular, the respiratory system.

\section{Methods}

A review of articles published in English in the last 5 years was conducted using the following. 1) PubMed database, according to the following MeSH terms and search strategies: "air pollution" and "fetal development"; "air pollution" and "prenatal exposure delayed effects"; "air pollution" and "respiratory symptoms and signs" or "respiratory infections" or "asthma" or "wheeze". The last strategy was restricted to the first year of life. 2) Web of Science Core Collection database, using the same terms as words in the text. We included prospective birth cohort studies that analyzed the relationship between prenatal exposure to at least one air pollutant and perinatal and childhood outcomes, because this study design allows the analysis of a possible causal relationship. Among 386 articles, we identified 27 studies on prospective birth cohorts (14 on fetal development and growth and 13 on respiratory disease), according to the inclusion criteria (Tables 1 and 2).

Studies with different designs, particularly meta-analysis, are cited in this article to complete and to improve the discussion on the main results of the birth cohorts. Because prospective cohort studies on this issue are recent, we considered that a period of 5 years could result in a satisfactory update on the possible effects of air pollution on fetal development and its impact on children's respiratory health.

\section{Exposure to air pollution and fetal development and growth}

Several follow-up studies have been conducted in recent decades to evaluate the impact of prenatal exposure to pollutants on fetal growth and development, with divergent results. The most frequently studied pollutants are nitrogen dioxide $\left(\mathrm{NO}_{2}\right), \mathrm{PM}$, polycyclic aromatic hydrocarbons (PAHs), and TS. I discuss TS in the following section of this article, separately. ${ }^{7-10}$ Such pollutant measurements may be performed using estimates of the distances between homes and roads with high traffic densities or via direct measurements of pollutants in the atmosphere by local monitoring stations associated with different dispersion models. Personal measurements may also be performed using portable devices or via the analysis of biological materials from exposed individuals. ${ }^{11-13}$ Among these studies, some prospective birth cohorts analyzed the effect of PM exposure on birth outcomes and have reported conflicting results. van den Hooven et al reported reduced fetal growth, negative impact on birth weight (BW), and positive association with small for gestational age (SGA) and premature birth (PB). The levels of exposure to PM were estimated using dispersion modeling at the home address. The higher levels of exposure were associated with smaller head circumference (HC) in the third trimester of pregnancy and with a reduction of $3.6 \mathrm{~g}$ in BW. The third quartile of $\mathrm{PM}_{10}$ exposure was associated with $\mathrm{PB}$ and SGA. The fourth quartile was also associated with PB. ${ }^{14}$ In contrast to the aforementioned results, Gehring et al reported no associations between prenatal PM exposure and BW. The maternal residential exposure to $\mathrm{PM}_{10}$ was estimated for births within the prevention and incidence of asthma and mite allergy (PIAMA) Dutch prospective cohort using temporally adjusted land-use regression (LUR) models. ${ }^{15}$ Pedersen et al compiled data from 14 prospective birth cohorts involving 12 European countries (European Study of Cohorts for Air Pollution Effects [ESCAPE]). The study pooled data from the following cohorts: Norwegian Mother and Child Study (MoBa) (Norway), Barn, Allergi, Milieu, Stockholm, Epidemiologisk undersökning (BAMSE) (Sweden), Danish National Birth Cohort (DNBC) (Denmark), Kaunus Neonatal Cohort (KANC) (Lithuania), Born in Bradford Cohort (BiB) (England), Amsterdam Born Children and Their Development (ABCD) (the Netherlands), GENERATION R (the Netherlands), PIAMA (the Netherlands), Duisburg Birth Cohort Study (DUISBURG) (Germany), Etude des Determinants Pre et Posnatals du Development et de la Santé de l'Enfant (EDEN) (France), Air Pollution and Pregnancy Outcomes (APREG) 
Table I Prospective birth cohort studies on effect of prenatal exposure to air pollutants and fetal/neonatal outcomes

\begin{tabular}{|c|c|c|}
\hline Author, year of publication & Prenatal exposure & Main results \\
\hline Slama et al, ${ }^{21} 2009$ & Benzene & Reduced $\mathrm{BW}$ and $\mathrm{HC}$ \\
\hline \multirow[t]{2}{*}{ Aguillera et al, ${ }^{18} 2010$} & BTEX & Reduced BPD \\
\hline & $\mathrm{NO}_{2}$ & $\begin{array}{l}\text { Reduced growth in HC, AC, BPD, and EFW } \\
\text { for those women who spent more time outdoor }\end{array}$ \\
\hline \multirow[t]{2}{*}{ Llop et al, ${ }^{23} 2010$} & $\mathrm{NO}_{2}$ & Increased risk for PB \\
\hline & Benzene & Increased risk for $\mathrm{PB}$ \\
\hline \multirow[t]{2}{*}{ Ballester et al, ${ }^{19} 2010$} & $\mathrm{NO}_{2}$ & Reduced length, weight, and $\mathrm{HC}$ at birth \\
\hline & & Positive association with SGA \\
\hline \multirow[t]{2}{*}{ Newman et al, ${ }^{61} 2010$} & Active MTS & Positive association with SGA and reduced BW \\
\hline & Passive MTS & No associations with birth outcomes \\
\hline \multirow[t]{2}{*}{ Estarlich et al, ${ }^{16} 201 \mathrm{l}$} & $\mathrm{NO}_{2}$ & Reduced length and weight at birth \\
\hline & Benzene & No association \\
\hline \multirow[t]{2}{*}{ Gehring et al, ${ }^{25} 201 \mathrm{I}$} & $\mathrm{NO}_{2}$ & Highest BW and lowest risk of SGA \\
\hline & & No association with PB \\
\hline \multirow[t]{2}{*}{ Gehring et al, ${ }^{15} 201 \mathrm{I}$} & $\mathrm{NO}_{2}$ and $\mathrm{PM}_{2.5}$ & No association between air pollutants and term \\
\hline & & BW \\
\hline \multirow[t]{2}{*}{ Iñiguez et al, ${ }^{17} 2012$} & $\mathrm{NO}_{2}$ & Reduced BPD, AC, and EFW \\
\hline & & Reduced neonatal length and $\mathrm{HC}$ \\
\hline \multirow[t]{2}{*}{ van den Hooven et al, ${ }^{14} 2012$} & $\mathrm{NO}_{2}$ and $\mathrm{PM}_{10}$ & Reduced fetal growth and BW \\
\hline & & Positive association with SGA and PB \\
\hline \multirow[t]{3}{*}{ Iñiguez et $a \mid,{ }^{58} 2012$} & MTS & \\
\hline & Active & Reduced BPD, AC, FL, and EFW \\
\hline & Passive & Reduced growth on BPD \\
\hline \multirow[t]{4}{*}{ Sunyer et al, ${ }^{65} 2012$} & MTS & \\
\hline & Active/passive & Reduced BW, increased risk for SGA \\
\hline & & Reduced BW for asthmatic mothers \\
\hline & & (no statistical significance) \\
\hline \multirow[t]{2}{*}{ Choi and Perera, ${ }^{32} 2012$} & $\mathrm{PAH}$ & PA - maternal obesity exacerbated the risk \\
\hline & & of exposure to $\mathrm{PAH}$ on reduced $\mathrm{BW}$ \\
\hline Ritz et al, ${ }^{22} 2014$ & TRAP, $\mathrm{NO}, \mathrm{NO}_{x}, \mathrm{NO}_{2}, \mathrm{CO}$, and & Reduced BPD \\
\hline & distance to monitoring station & \\
\hline
\end{tabular}

Abbreviations: BW, birth weight; HC, head circumference; BTEX, aromatic hydrocarbons (benzene, toluene, ethylbenzene, m-/P-xylene, and o-xylene); BPD, biparietal diameter; $\mathrm{NO}_{2}$, nitrogen dioxide; $\mathrm{AC}$, abdominal circumference; EFW, estimated fetal weight; SGA, small for gestational age; MTS, maternal tobacco smoking; PB, premature birth; PM, particulate matter; FL, femur length; PAH, polycyclic aromatic hydrocarbons; TRAP, twin reversed arterial perfusion; NO, nitric oxide; NO, nitrogen oxides; $\mathrm{CO}$, carbon monoxide.

(Hungary), Genetica e Ambiente: Studio Prospectivo dell' Infanzia in Italia (GASPII) (Italy), Infancia y medio ambiente (INMA) (Spain), and Rhea study (Greece). Increase of $5 \mu \mathrm{g} / \mathrm{m}^{3}$ in prenatal exposure to $\mathrm{PM}_{2.5}$ and $\mathrm{PM}_{10}$ was associated with an increased risk of low birth weight (LBW) (odds ratio [OR]: 1.18; $95 \%$ CI: $1.06-1.33$ and OR: 1.16 ; $95 \%$ CI: $1.00-1.35$, respectively). Even exposures to $\mathrm{PM}_{2.5}$ concentrations below the minimum recommended by the European Union were also associated with an increased risk of LBW. ${ }^{9}$ The meta-analysis undertaken by Sapkota et al also noted a negative correlation between exposure to $\mathrm{PM}_{10}$ and LBW, but this correlation was not significant. ${ }^{10}$ Several meta-analyses, including prospective and retrospective studies, have considered the effects of exposure to PM on birth outcomes with more consistent results about the negative impact on fetal development. ${ }^{7-10}$ Recent metaanalyses have examined the results of the effects of prenatal exposure to PM on the BWs of infants born at term. According to the effects estimated by 14 participating centers from nine countries (International Collaboration on Air Pollution and Pregnancy Outcomes [ICAPPO]) that have applied a common protocol totaling approximately 3 million births, a increase of $10 \mu \mathrm{g} / \mathrm{m}^{3}$ throughout pregnancy in $\mathrm{PM}_{10}$ exposure (OR: 1.03; 95\% CI: 1.01-1.05) and in $\mathrm{PM}_{2.5}$ exposure (OR: 1.10; 95\% CI: 1.03-1.18) has been associated with decreased BW. This increase in exposure to $\mathrm{PM}_{10}$ contributed to a reduction in $\mathrm{BW}$ of $8.9 \mathrm{~g}$. There was a tendency to report stronger associations at the centers with higher average concentrations of $\mathrm{PM}_{2.5}$, with higher ratios of $\mathrm{PM}_{2.5} / \mathrm{PM}_{10}$, and that used a temporal approach. ${ }^{7}$

The effects on the fetus were also observed in the meta-analysis undertaken by Zhu et al which included 25 observational studies. Increased exposure to $\mathrm{PM}_{2.5}$ was directly associated with LBW (OR: 5.1; 95\% CI: 1.02-1.07), prematurity (OR: $1.10 ; 95 \%$ CI: $1.03-1.18$ ), and SGA infants (OR: 1.15; 95\% CI: 1.10-1.20). A $10 \mu \mathrm{g} / \mathrm{m}^{3}$ increase in $\mathrm{PM}_{10}$ exposure was associated with a $14.8 \mathrm{~g}(95 \% \mathrm{CI}$ : 9.86-19.31) decrease in $\mathrm{BW}^{8}$ The impacts on BW noted in 
Table 2 Prospective birth cohort studies on effect of prenatal exposure to air pollutants on respiratory disease

\begin{tabular}{|c|c|c|}
\hline Author, year of publication & Prenatal exposure & Main results \\
\hline Jedrychowski et al, ${ }^{41} 2010$ & PAH-DNA adducts & PA - wheezing days during first 2 years of life \\
\hline Jedrychowski et al, ${ }^{39} 2010$ & $\mathrm{PM}_{2.5}$ & Reduced FVC and FEV,$-0-5$ years of age \\
\hline Ruskamp et al, ${ }^{67} 2010$ & Maternal tobacco & Atopy increased risk of RI among children whose \\
\hline \multirow[t]{2}{*}{ Prabhu et al, ${ }^{63} 2010$} & $\begin{array}{l}\text { smoking } \\
\text { MTS }\end{array}$ & $\begin{array}{l}\text { mothers smoked during pregnancy } \\
\text { PA - asthma and reduced lung function at } 2 \text { years of age }\end{array}$ \\
\hline & & Quit smoking during early pregnancy: increased risk \\
\hline Esplugues et al, ${ }^{46} 201 \mathrm{I}$ & $\mathrm{NO}_{2}$ & $\begin{array}{l}\text { of asthma at } 2 \text { years of life with normal lung function } \\
\text { PA not statistically significant with respiratory infection, }\end{array}$ \\
\hline \multirow[t]{3}{*}{ Rosa et al, ${ }^{43} 201 \mathrm{l}$} & $\mathrm{PAH}$ & No association with asthma at 5-6 years \\
\hline & $\mathrm{PAH}+\mathrm{MTS}$ & PA - asthma at $5-6$ years of age \\
\hline & & $\begin{array}{l}\text { Not significant association with lgE level at } 5-6 \text { years } \\
\text { of age }\end{array}$ \\
\hline Duijts et al, ${ }^{57} 2012$ & MTS & PA - wheezing at $\mathrm{I}-4$ years of age \\
\hline Robison et al, ${ }^{66} 2012$ & MTS & No association with wheezing \\
\hline \multirow[t]{2}{*}{ Gehring et al, ${ }^{38} 2013$} & $\mathrm{NO}_{x}, \mathrm{NO}_{2}$, and $\mathrm{PM}_{2.5}$ & $\begin{array}{l}\text { Interaction between MTS and PB on wheezing } \\
\text { PA - levels of pollutants at the current address }\end{array}$ \\
\hline & & with small decreases in lung function \\
\hline Jedrychowski et al, ${ }^{55} 2013$ & $\mathrm{PM}_{25}$ & $\begin{array}{l}\text { No association of level of pollutants at birth address } \\
\text { PA - bronchopulmonary infections }\end{array}$ \\
\hline Jedrychowscki et al, ${ }^{42} 2014$ & $\mathrm{PAH}$ & PA - wheezing severity \\
\hline \multirow[t]{2}{*}{ Chiu et al, ${ }^{44} 2014$} & Black carbon and & PA - wheezing in early childhood \\
\hline & $\mathrm{PM}_{2.5}$ & $\begin{array}{l}\text { Interaction with prenatal community } \\
\text { violence was suggested }\end{array}$ \\
\hline Jedrychowski et al, ${ }^{40} 2015$ & $\mathrm{PAH}$ & Reduced $\mathrm{FEV}_{1}$ and $\mathrm{FEV}_{25-75}$ \\
\hline
\end{tabular}

Abbreviations: PAH, polycyclic aromatic hydrocarbons; PA, positive association; PM, particulate matter; FVC, forced vital capacity; FEV , forced expiratory volume in I second; RI, respiratory infection; MTS, maternal tobacco smoking; $\mathrm{NO}_{2}$, nitrogen dioxide; $\mathrm{PB}$, premature birth; $\mathrm{NO}_{\mathrm{x}}$, nitrogen oxides.

several studies may seem small individually because they represent only a few grams of reduction; however, the great worldwide exposure and population impact make the effects an important public health problem. Pedersen et al estimated that a reduction in the number of cases of LBW of $22 \%$ could be achieved by reducing exposure to $\mathrm{PM}_{2.5}$ to $10 \mu \mathrm{g} / \mathrm{m}^{3}$ during pregnancy. ${ }^{9}$ Prenatal exposure to $\mathrm{NO}_{2}$ has also been widely evaluated in birth cohorts, which have linked said exposure to low BW and intrauterine growth restriction in children born both at term and preterm..$^{9,14-20}$

In a multicenter study conducted in Spain, Estarlich et al reported the relationship between an increase of $10 \mu \mathrm{g} / \mathrm{m}^{3}$ in $\mathrm{NO}_{2}$ exposure during pregnancy and a reduction of $0.9 \mathrm{~mm}$ (95\% CI: -1.8 to -0.1 ) in stature at birth. This relationship was even stronger among women who remained at home for at least 15 hours per day; a height reduction of $0.16 \mathrm{~mm}$ (95\% CI: -0.27 to -0.04 ) and a BW reduction of $22 \mathrm{~g}$ were also noted secondary to the same increase in $\mathrm{NO}_{2}$ during the second trimester of pregnancy. In this cohort, the effects of benzene exposure on fetal development were also studied, although no significant results were obtained. ${ }^{16}$ Consistent with these results, the meta-analysis that included 14 European cohorts (ESCAPE) demonstrated that increased exposure to $\mathrm{NO}_{2}$ was associated with decreased $\mathrm{BW}(\mathrm{OR}: 9.1 ; 95 \% \mathrm{CI}$ :
1.00-1.19) and a greater risk of low BW among individuals living near high-density vehicular traffic routes, with an OR of 1.0 (95\% CI: 1.01-1.11). ${ }^{9}$ Only a limited number of studies have followed fetal growth and development during pregnancy, which may help to clarify the possible windows of susceptibility that exist during intrauterine life. Recent research undertaken in Spain demonstrates that both early and mid-pregnancy represent periods of increased susceptibility. Exposure to $\mathrm{NO}_{2}$, as estimated by LUR according to home addresses, indicated that an increased susceptibility existed during a critical window during early pregnancy, before the 20th week of gestation. Biparietal diameter (BPD) and femur length were both affected early in 20th week. Neonatal outcomes (height and HC at birth) were inversely associated with $\mathrm{NO}_{2}$ exposure during this period. Exposure during the 32nd week of pregnancy was inversely associated with $\mathrm{BPD}, \mathrm{HC}$, and estimated BW. It was also inversely associated with the growth of these parameters between weeks 20 and 32. ${ }^{17}$ In a multicenter study (INMA Sabadell), a follow-up analysis was conducted using ultrasound to assess the impact of traffic related air pollution (TRAP) on fetal growth. $\mathrm{NO}_{2}$ and aromatic hydrocarbon exposure were analyzed. The level of exposure was inversely associated with BPD growth during weeks $20-32$. There were no relationships noted involving the other fetal growth parameters. Among the 
women who spent less than 2 hours/day outside of their homes, significant negative correlations between $\mathrm{NO}_{2}$ and $\mathrm{HC}$ growth during weeks 12-20 were noted, as were correlations involving abdominal circumference, BPD, and fetal weight during weeks 20-32. The results of this cohort were also indicative of the negative effect of $\mathrm{NO}_{2}$ exposure during both early and mid-pregnancy. ${ }^{18}$ Consistent with these results, a birth cohort study conducted in Valencia, Spain noted that high levels of $\mathrm{NO}_{2}$ exposure during the first trimester were associated with a reduction in height of $0.27 \mathrm{~cm}$ and a reduction in $\mathrm{BW}$ of $40.3 \mathrm{~g}$. The same level of exposure throughout pregnancy was associated with a reduction of $0.17 \mathrm{~cm}$. The increase in $\mathrm{NO}_{2}$ exposure during the second trimester was associated with SGA, $\mathrm{BW}$, and height. ${ }^{19}$ However, there is also evidence regarding the adverse effects of exposure to pollution during late gestation. In the Netherlands, $\mathrm{NO}_{2}$ levels correlated inversely with the fetal femur length at both second and third trimesters. Both $\mathrm{PM}_{10}$ and $\mathrm{NO}_{2}$ exposure were associated with decreased $\mathrm{HC}$ during the third trimester. The analysis of neonatal outcomes demonstrated that the average levels of both $\mathrm{PM}_{10}$ and $\mathrm{NO}_{2}$ during pregnancy were not associated with $\mathrm{HC}$ or height either at birth or during the neonatal period; however, they correlated inversely with BW. Increased exposure to $\mathrm{PM}_{10}$ was also associated with prematurity. The authors found no relationship between $\mathrm{NO}_{2}$ exposure and adverse outcomes at birth. ${ }^{14}$ Pereira et al also demonstrated greater effects on $\mathrm{BW}$ and the incidence of SGA infants among women with higher levels of exposure during mid-to-late pregnancy; 23,452 pregnant women were studied in a retrospective cohort, and residential exposure to $\mathrm{NO}_{2}$ was measured. Increased exposure during the second trimester was associated with fetal growth restriction (OR: 1.31 ; 95\% CI: $1.08-1.69) .{ }^{20}$ In addition to both PM and $\mathrm{NO}_{2}$, other pollutants have also proven harmful to fetal development. ${ }^{21,22}$ Slama et al analyzed the effects of exposure to benzene on fetal growth as part of the mother-child EDEN cohort study conducted in France. The difference between this study and previous studies was its analysis of personal exposure. Pregnant nonsmokers carried a device to measure their exposure to benzene for a week, at 27 weeks gestation. Benzene exposure was associated with lower BW and $\mathrm{HC}$, as measured both during pregnancy (via ultrasound) and at birth. The effects were linked to benzene itself and to the effects of traffic and urban pollution. ${ }^{21}$ Also, Llop et al have reported associations of benzene prenatal exposure with $\mathrm{PB} .{ }^{23}$ However, some prospective cohorts have not found negative effects of prenatal exposure to benzene on fetal development. ${ }^{15,16}$ Estarlich et al reported no associations between exposure to benzene and neonatal outcomes (length and weight at birth). ${ }^{16}$
Other birth cohorts also evaluated the role of PAH on fetal development. A comparative study of two cohorts in People's Republic of China examined the effects exerted by PAH both before and after the closure of a coal plant. There was an increase in the $\mathrm{HC}$ of the children whose pregnancies occurred after the close of the plant. This effect coincided with a significant reduction in the levels of PAH-DNA adducts (an exposure marker for a dose-dependent analysis) in umbilical cord blood and lower levels of environmental PAH following the closing of the plant. ${ }^{24} \mathrm{HC}$ reduction suggests a reduction in brain volume and was noted by Pedersen et al. ${ }^{9}$ However, some studies have noted positive correlations between exposures to pollutants and perinatal parameters. In the Netherlands, the ABCD birth cohort study evaluated the effects of $\mathrm{NO}_{2}$ exposure on the pregnancies of 7,600 women, using the LUR model temporally adjusted. The children born to women with the highest levels of $\mathrm{NO}_{2}$ exposure had the highest BW and lowest risks of being SGA. No change in the incidence of prematurity was noted..$^{25}$ In the Netherlands, the birth cohort Dutch PIAMA study evaluated 3,853 pregnant women exposed to $\mathrm{NO}_{2}, \mathrm{PM}_{2.5}$, and soot during the entire pregnancy, during each trimester, and during the final month. Exposure levels were not associated with outcomes at term. There was no significant correlation between soot exposure throughout pregnancy and during the final month of pregnancy, and prematurity. ${ }^{15}$ A historical cohort study (PAMPER study) analyzed data from pregnancies between 1962 and 1992, including 90,537 births and 812 abortions, in northern England. The black smoke emission data were collected from 20 monitoring stations during the study period. The authors noted no relationships between exposure to PM during pregnancy and the risk of miscarriage, as was the case in the meta-analysis undertaken by Zhu et al. ${ }^{8,26}$ PAMPER study also noted no relationships with preterm birth; however, there was a significant negative correlation between greater levels of exposure and BW. ${ }^{26}$ In the same cohort among 88,679 births, a significant interaction between social and economic deprivation and exposure to black smoke, which intensified the negative effect of exposure on BW, was observed. ${ }^{27}$ Some birth cohorts measured the exposure to TRAP by analyzing the distances of residential roads with high densities of vehicle traffic. Other cohort studies used the same method to evaluate the effects of TRAP exposure during both the neonatal period and childhood. A significant impact on the respiratory health was noted after neonatal exposure, ${ }^{13}$ however, no significant impact following prenatal exposure was noted. Hannam et al noted no significant relationships involving distances less than $200 \mathrm{~m}$ and SGA, LBW, and PB, with adjustments for 
maternal age, ethnicity, socioeconomic status, parity, birth season, smoking, and body mass index. ${ }^{28}$ In the Netherlands, van den Hooven et al noted no increased risk for BW, prematurity, SGA, and maternal outcomes in 7,339 pregnant women and newborns living within $150 \mathrm{~m}$ of major roads. ${ }^{29}$ Several factors may have contributed to the different results noted for each of the aforementioned studies. In addition to the differences in the methods used, population characteristics may also interfere with study results. Habits, lifestyles, and both socioeconomic and demographic conditions may be associated with different levels of exposure to air pollutants. In the multicenter birth cohort INMA, which was developed in Valencia, Spain, younger women, Latin Americans, and women belonging to lower social strata were exposed to higher levels of $\mathrm{NO}_{2} \cdot{ }^{11}$ However, there exists controversy about this particular finding. A birth cohort included 2,000 pregnant women. Questionnaires were used, and measurements of $\mathrm{NO}_{2}$, trihalomethanes (an aqueous marker of disinfection), organochlorines, and other biomarkers were taken. The results are questionable as to whether socioeconomic disadvantages are associated with higher levels of exposure to environmental pollutants. ${ }^{30}$ In addition to these variables, nutritional status during pregnancy is also related to fetal development. In addition to an inadequate supply as a result of inadequate maternal food intake, maternal morbidities such as hypertension and diabetes may compromise the supply of nutrition to the fetus. ${ }^{31}$

Some studies have sought to understand the mechanisms by which fetal development may be impaired following exposure to air pollutants. An analysis of growth markers and placental function that included 7,801 pregnant women in the Netherlands utilized dispersion models to estimate $\mathrm{NO}_{2}$ and $\mathrm{PM}_{10}$ at residential addresses. Placental growth factor (proangiogenic) and fms like tyrosine soluble kinase (antiangiogenic) were each measured during both the first and second trimesters in both maternal blood and cord blood. Umbilical artery pulsatility and uterine artery pulsatility were measured using USG-Doppler at second and third trimesters; placental alterations were assessed during the third trimester, and both placental weight and BW were measured. Higher levels of $\mathrm{NO}_{2}$ and $\mathrm{PM}_{10}$ were associated with lower levels of maternal blood markers during both the second and third trimesters. Throughout pregnancy, the highest levels of exposure to $\mathrm{PM}_{10}$ and $\mathrm{NO}_{2}$ were associated with an antiangiogenic state in cord blood. ${ }^{32}$

\section{Exposure to air pollution and lung disease}

BW is often used as a marker of fetal growth; however, the effect of air pollutants exposure might be significant on susceptible fetal organs such as lung. Mounting evidence exists regarding the effects of exposure to environmental air pollution on the development of children's respiratory tract and, consequently, on respiratory morbidity and mortality. ${ }^{1,33-35}$ Possible susceptibility windows occur during both the prenatal and postnatal periods because the growth and development of the respiratory system begins during fetal life (embryonic, pseudoglandular, canalicular, saccular, and alveolar stages) and extends into adolescence. Throughout this process, external aggression may result in changes that compromise the respiratory health of the individual with effects during both childhood and adulthood. Both genetic and epigenetic characteristics are important in this process. ${ }^{34}$ Among the studies regarding the effect of postnatal exposure, long-term contact with $\mathrm{PM}_{10}$ and $\mathrm{NO}_{2}$ between birth and 11 years of age has been associated with a lower increase in forced expiratory volume in 1 second $\left(\mathrm{FEV}_{1}\right)$, according to spirometric analyses performed at 3 years, 5 years, 8 years, and 11 years of age (MAAS - Manchester Asthma and Allergy Study). ${ }^{36}$ In Sweden, a birth cohort (BAMSE) included 1,900 children up to 8 years of age who were subjected to questionnaires, spirometry, and assessment of $\operatorname{IgE}$ and $\mathrm{PM}_{10}$ levels at their home addresses, schools, and daycares, using a dispersion model. Children with the highest levels of exposure to $\mathrm{PM}_{10}$ during their first year of life exhibited a decreased $\mathrm{FEV}_{1}$ at 8 years of age, which was more pronounced in children who were sensitized to both inhaled allergens and food allergens. ${ }^{37}$

Moreover, the results of the analyses of five cohort studies in four European countries (Germany, Sweden, the Netherlands, and the UK) were suggestive of a significant effect exerted by postnatal exposure, but not by prenatal exposure. Long-term exposure to both $\mathrm{PM}_{2.5}$ and $\mathrm{NO}_{2}$ was associated with significant but small reductions in lung volume growth in school age children. The negative correlations involved current addresses as opposed to birth addresses. ${ }^{38}$

Although some prospective birth cohorts have assessed the impact of postnatal exposure on the development and function of the respiratory system, information regarding the effects of exposure during intrauterine life is both scarce and controversial. ${ }^{26,35}$ Prematurity and low BW as a result of prenatal exposure alone may also reflect on the likelihood of developing respiratory disease because they are responsible for the elevated risk of mortality and respiratory disease during subsequent years. ${ }^{35}$ In a follow-up study, personal measurements of $\mathrm{PM}_{2.5}$ were performed over 48 hours in the second trimester of pregnancy. Children were followed for $0-5$ years. Deficits in forced vital capacity $(\mathrm{FVC})$ and $\mathrm{FEV}_{1}$ 
were reported at the highest quartile of $\mathrm{PM}_{2.5}{ }^{39}$ Other recent evidence suggests that prenatal exposure to PAHs may affect lung development and that this effect may be exacerbated by postnatal exposures. Jedrychowski et al evaluated 195 children without asthma of non-smoking mothers. The highest levels of PAHs during pregnancy were associated with a reduced $\mathrm{FEV}_{1}$ and a reduced $\mathrm{FEV}_{25-75^{\circ}}{ }^{40}$ The same authors have reported that the number of wheezing days during the first 2 years of life was positively associated with the prenatal level of PAH-adducts (incidence rate ratio [IRR] $=1.69 ; 95 \%$ CI: 1.52-2.88). ${ }^{41}$ Correlations among personal exposure, preand postnatal $\mathrm{PAH}$, and the severity of wheezing and recurrent wheezing were also studied by the same group of researchers and suggested that prenatal exposure may trigger and intensify the symptoms resulting from postnatal exposure. The study also found IRR $=1.53$ (95\% CI: $1.43-1.64)$ for both prenatal exposure and wheezing severity and IRR $=1.13$ (95\% CI: 1.08-1.19) for postnatal exposure. The recurrence of wheezing was more commonly associated with exposure during the first 3 years of life (OR: 2.31; 95\% CI: 1.26-4.22) than with prenatal exposure (OR: 1.40; 95\% CI: $0.85-2.09) .{ }^{42}$ Rosa et al also studied prenatal exposure to $\mathrm{PAH}$. The authors reported no association with asthma at 5-6 years of age. However, they reported a positive but not significant association of combined prenatal exposure to PAH and maternal TS with asthma at the same age, but not with IgE levels. ${ }^{43}$

The evidence regarding the effects of pollutants on the onset of respiratory symptoms and aggravation of existing morbidities is strong. However, another important but less studied phenomenon is the possible effects of TRAP as a determining factor in the induction of asthma/wheezing and allergy. The results of cohort studies remain controversial. Inconsistencies among the findings of these studies may be attributed to differences in the scenarios of the studies, designs, and exposure measurement methods. ${ }^{44,45}$ In Spain, 352 children were followed. Prenatal exposure to $\mathrm{NO}_{2}$ was accessed using home addresses (LUR) and postnatal exposure both inside and outside the home, as determined with passive devices for 14 days. For each increment of $10 \mu \mathrm{g} / \mathrm{m}^{3}$ of outdoor postnatal $\mathrm{NO}_{2}$ exposure, the $\mathrm{OR}$ for persistent cough during the first year of life was 1.40 (95\% CI: 1.02-1.92). Trends were also noted for bronchiolitis, bronchitis, lower respiratory tract infection, wheezing and persistent cough, and prenatal exposure, but these trends were not significant. ${ }^{46}$ Based on the results of a longitudinal study involving children between 0 year and 5 years of age, children living near roads with higher traffic densities are subject to more instances of chronic respiratory disease, most likely as a result of repeated exposures early in life, which may be cumulative. ${ }^{45}$ Two cohort studies performed in three regions of Germany (GINIplus and LISAplus) followed children from birth to 10 years of age via questionnaires, blood tests, and measurements of pollutants $\left(\mathrm{NO}_{2}, \mathrm{PM}_{2.5}, \mathrm{PM}_{2.5}\right.$, and $\mathrm{O}_{3}$ absorbance $)$. Evidence that exposure to TRAP influences the prevalence of asthma, allergic rhinitis, or sensitization to aeroallergens was uncovered, and significant heterogeneity was observed among the three regions studied. ${ }^{47}$ The role of postnatal exposure in the induction of asthma/allergy also is not clear. In New York, a cohort study involving 408 children between 5 years and 6 years of age was undertaken between 2005 and 2011. The highest incidence of new cases of wheezing was noted among the children with the most exposure to $\mathrm{PM}_{2.5}$, which suggested that exposure to indoor pollution during childhood contributes to the development of wheezing after 5-7 years of age. There was no correlation with IgE levels. ${ }^{45}$ Evidence has been drawn from studies examining markers of immune function and the effects of prenatal exposure to $\mathrm{PM}_{10}$ and $\mathrm{NO}_{2}$ on the immune system of the newborn. During a follow-up study involving 370 women, the levels of volatile compounds were measured both 3 months prior to pregnancy and during pregnancy in a subgroup of 56 non-smoking women. The findings of this study suggest that maternal exposure to air pollutants both before and during pregnancy may alter the development of an infant's immune system, which may increase the infant's risk of asthma and allergies. Higher $\mathrm{PM}_{10}$ levels were associated with reduced percentages of CD $4+\mathrm{CD} 25$ + cord blood at 3 months before pregnancy. A similar reduction was observed following exposure to benzene. A similar trend was observed between $\mathrm{NO}_{2}$ and CD4 + $\mathrm{CD} 25+\mathrm{T}$ cells, but the effect was the strongest between $\mathrm{NO}_{2}$ exposure and CD $8+$ T cells. ${ }^{48}$ In a birth cohort that included 265 healthy subjects, moderate exposure to both indoor and outdoor pollutants resulted in changes in cytokine levels in cord blood. The highest $\mathrm{PM}_{10}$ exposure levels during the final 3 days of gestation were associated with a reduction in IL-10 and during the last 3 months of pregnancy were associated with increased IL-1 $\beta$ levels, both in the umbilical cord. Maternal smoking was associated with reduced IL-6 levels. There were no relationships involving other IL types in the cord blood. ${ }^{49}$ Another important aspect of the exposure to pollutants is its relationship with susceptibility to respiratory infections during childhood. Mounting evidence exists regarding the impact of postnatal exposure to pollutants on both the incidence and the severity of respiratory symptoms during the early years of life. ${ }^{50-52}$ Follow-up studies have demonstrated that every hour of postnatal exposure to $\mathrm{PM}_{2.5}$ 
at levels $>100 \mu \mathrm{g} / \mathrm{m}^{3}$ was associated with an increase of $7 \%$ in the risk of developing a respiratory infection during the first year of life. ${ }^{50}$ There is also evidence of a significant relationship between air pollution and the severity of respiratory symptoms, particularly during the week following the development of a respiratory infection as well as among infants with prior pulmonary function changes. Stern et al reported that increased $\mathrm{PM}_{10}\left(>33.3 \mu \mathrm{g} / \mathrm{m}^{3}\right)$ coincided with an increase of $20 \%$ in the duration of respiratory infections. ${ }^{51}$ Additionally, the exposure of school age children to pollutants is associated with respiratory morbidity. A study of schoolchildren's personal and indoor levels of exposure to both $\mathrm{NO}_{2}$ and $\mathrm{O}_{3}$ showed that these exposures were associated with greater risks of pneumonia. ${ }^{52}$

However, there is little information regarding the possible effects of air pollutants during pregnancy and individuals' subsequent susceptibility to infections during childhood. Among the studies that analyzed the impact of prenatal exposure, a retrospective cohort conducted in Boston, MA, USA, examined 1,263 mother-children couples from 1999 to 2002 . The results suggest that living near a large highway during pregnancy increases the risk of respiratory infections during the first years of life. ${ }^{53}$

Among the prospective birth cohorts, a study conducted by Aguilera et al in four regions of Spain described an increased risk of respiratory infections and ear infections following increased $\mathrm{NO}_{2}$ exposure and, to a lesser extent, following exposure to benzene during the first years of life. An increase in $\mathrm{NO}_{2}$ exposure of $10 \mu \mathrm{g} / \mathrm{m}^{3}$ during pregnancy was associated with an increased risk of lower respiratory tract infection (relative risk [RR] $=1.05 ; 95 \%$ CI: 0.98-1.12). In this study, the results were suggestive of a trend; however, because interdependency existed among the variables during both pregnancy and the early years of life, it was not possible to analyze each exposure period separately. ${ }^{54}$ According to the results of the birth cohort study in Valencia, Spain, the authors have found not statistically significant correlation between prenatal exposure to $\mathrm{NO}_{2}$ and bronchitis, bronchiolitis, lower respiratory tract infections, wheeze, and persistent cough. ${ }^{46}$ Jedrychowscki et al analyzed the effects of exposure to PM. In a follow-up study, 214 children had personal prenatal $\mathrm{PM}_{2.5}$ exposure measurements. The incidence of bronchopulmonary infections was correlated with the prenatal exposure in a dose-response manner (OR: 2.44; 95\% CI: 1.22-5.36). ${ }^{55}$

\section{Exposure to TS during pregnancy}

Strong evidence links exposure to TS during both pre- and postnatal periods to the occurrence of health problems in children. ${ }^{56-67}$ TS contains over 4,000 chemicals, at least 250 of which are toxic to the human body and more than 50 are carcinogenic. Passive smoking is associated with both cardiovascular and respiratory diseases in both adults and children. ${ }^{1}$

The toxic components of TS may reach the fetus by crossing the placenta; they may also be transmitted to an infant via breast milk. ${ }^{56}$ However, differentiating among the specific effects of prenatal or postnatal exposures on the development of infants is difficult because children exposed in utero invariably remain exposed following birth.

Evidence is accumulating regarding the relationship between prenatal exposure to TS and neonatal outcomes related to fetal growth and development. The aforementioned studies also assessed the impact of TS on the development of respiratory disorders among children, particularly the occurrence of respiratory infections and asthma/allergy symptoms. A growing number of studies have also analyzed the impact of TS on neurodevelopment. ${ }^{56,59,60}$

The study of birth cohorts has confirmed the existence of several relationships and has sought to analyze the potential for the existence of greater vulnerability windows during pregnancy. ${ }^{58}$ Iñiguez et al studied the role of maternal smoking in a cohort study conducted in Spain. Relationships were observed between BPD, abdominal circumference, femur length, and estimated fetal weight, as measured via ultrasound between 32 nd week and 38th week of gestation. Maternal smoking also adversely affected growth between 20th week and 32nd week, 12th week and 32nd week, and 12 th week and 38 th week of gestation. Exposure to environmental TS (passive smoking) was also inversely associated with increased BPD in each of the analyzed windows, with the exception between 32 nd week and 38 th week. ${ }^{58}$

However, there have been mixed results noted regarding the role of passive maternal smoking during pregnancy. A cohort study was conducted comparing 2,210 pregnant women with mild and moderate-severe asthma with women who were not exposed to TS, active smokers, and passive smokers. Although the authors observed a greater risk of SGA newborns $(P<0.001)$ and lower mean BW $(P<0.001)$ among smoking mothers, no differences were observed in maternal and neonatal outcomes among passive smokers and nonsmokers. ${ }^{61}$

The risk of recurrent wheezing in infants also appears to be influenced by smoking during pregnancy. Maternal smoking during the third trimester has been associated with an increased risk of recurrent wheezing within the first 2 years of life (OR: 3.5; 95\% CI: 1.2-10.7), according to the exposure assessments performed via questionnaires given 
to the children's parents. The results were similar when the evaluation utilized cotinine measurements in both umbilical cord blood and urine at 1 year of age. In this study, maternal smoking did not significantly influence the incidence of recurrent wheezing or bronchial hyperresponsiveness within the first 7 years of life. ${ }^{62}$

Smoking cessation during pregnancy may have benefits but may not completely eliminate the risk of respiratory effects in children. Another longitudinal study observed that children with mothers who smoked throughout pregnancy had a higher incidence of respiratory symptoms and reduced lung function as determined via spirometry compared with the children of nonsmokers. Children with mothers who quit smoking during early pregnancy also had an increased risk of asthma in the first 2 years of life; however, these children exhibited normal lung function. ${ }^{63}$

The role of passive smoking has been studied in a birth cohort that followed more than 4,000 children up to 16 years of age. The likelihood of developing asthma was higher among the children of passive smoking mothers (OR: 1.45; 95\% CI: 1.15-1.83). The high risk remained significant after adjusting for parental smoking during childhood. A standard dose-dependent relationship with exposure to TS was observed. Passive smoking during childhood was also associated with asthma, rhinitis, and eczema. Analyses conducted by age demonstrated that asthma and rhinitis occurred primarily during childhood and that eczema occurred later. ${ }^{64}$ Sunyer et al also reported negative effects of the maternal exposure to second-hand TS on BW and increased risk for SGA. ${ }^{65}$

Despite the large number of animal studies evaluating the potential of cigarette smoke exposure during intrauterine life to induce asthma/allergy, the number of birth cohort studies evaluating this outcome is small. ${ }^{56}$ Animal studies have demonstrated the presence of larger alveoli among rats exposed to TS during intrauterine life. Similar effects have been reported in animals exposed to nicotine during pregnancy. The formation of the airways also appears to be affected by exposure to nicotine in experimental animal studies. ${ }^{26}$ In a recent meta-analysis, Burke et al observed a higher incidence of wheezing and asthma at age 2 years in children who were exposed to TS during either the prenatal or the postnatal period. The incidence of wheezing ranged from $30 \%$ to $70 \%$, and the incidence of asthma ranged from $21 \%$ to $85 \%$. The greatest impact on the incidence of wheezing was reported among children of smoking mothers following exposure during the postnatal period (OR: 1.70; 95\% CI: 1.24-2.35), and the greatest impact on the incidence of asthma was reported among children of smoking mothers following exposure during the prenatal period (OR: 1.85; 95\% CI: 1.35-2.53). Of the 79 included studies, the authors selected four studies that analyzed the incidence of wheezing and five studies that analyzed the incidence of asthma. ${ }^{56} \mathrm{In}$ clinical situations such as prematurity, the effects of TS exposure may be increased. A cohort study including 1,448 children in Boston demonstrated that exposure to TS during pregnancy was not associated with the incidence of wheezing (OR: 1.1; 95\% CI: 0.5-2.4). However, an analysis of a subgroup composed of premature infants demonstrated that TS exposure potentiated the risk of wheezing (OR: 2.0; 95\% CI: 1.3-3.1 for prematurity and OR: $3.8,95 \% \mathrm{CI}: 1.8-8.0$ for prematurity associated with intrauterine exposure to TS). ${ }^{66}$

In addition to prematurity, genetic characteristics may also influence the risk of developing wheezing among children who have been exposed to TS during intrauterine life. In a study undertaken by Ruskamp et al atopy, as determined via total IgE levels and the presence of neonatal dermatitis, increased the risk of respiratory infections among children whose mothers smoked during pregnancy (OR: 6.18; 95\% CI: 1.45-26.34 and OR: 5.69; 95\% CI: 2.01-16.04, respectively). ${ }^{67}$

\section{Conclusion}

Great heterogeneity exists among studies that have analyzed evidence regarding the impact of intrauterine exposure to air pollutants on fetal growth and development. The largest reported effects are associated with prenatal exposure to $\mathrm{PM}, \mathrm{NO}_{2}$, and TS. There are more conflicting results on the effects of the prenatal exposure to PAH.

The primary effects of prenatal pollutants exposure affect particularly $\mathrm{BW}$ and other parameters of fetal biometry. There is strong evidence regarding the impact of $\mathrm{PM}$ and $\mathrm{NO}_{2}$ on wheezing and respiratory infection in infancy but not on the role of the pollutants in the induction of asthma.

There is a need for additional prospective cohorts that begin in early pregnancy with follow-up to the children's first years of life that may provide information on causal relationships. The main aspects to be clarified include the role of specific pollutants, prenatal windows of vulnerability, and the importance of confounders as socioeconomics status and nutrition.

Growing evidence links maternal smoking to fetal development and to the symptoms and induction of childhood asthma. Concerning TS, there is a need of studies on the effects of maternal second-hand TS exposure and on the role of smoking cessation during pregnancy.

A better knowledge on the impact of prenatal exposure to air pollutants can help to improve public policies and 
prophylactic strategies regarding the children and consequently adult's health.

\section{Disclosure}

The author reports no conflicts of interest in this work.

\section{References}

1. Who.int (homepage on the internet). World Health Organization. Available from: www.who.int/mediacentre/factsheets/fs313/en. Accessed January 5, 2015.

2. Lim SS, Vos T, Flaxman AD, et al. A comparative risk assessment of burden of disease and injury attributable to 67 risk factors and risk factor clusters in 21 regions, 1990-2010: a systematic analysis for the Global Burden of Disease Study 2010. Lancet. 2012;380(9859):2224-2260.

3. Riva DR, Magalhães CB, Lopes AA, et al. Low dose of fine particulate matter (PM2.5) can induce acute oxidative stress, inflammation and pulmonary impairment in healthy mice. Inhal Toxicol. 2011; 23(5):257-267.

4. Yoshizaki K, Brito JM, Toledo AC, et al. Subchronic effects of nasally instilled diesel exhaust particulates on the nasal and airway epithelia in mice. Inhal Toxicol. 2010;22(7):610-617.

5. Mauad T, Rivero DH, de Oliveira RC, et al. Chronic exposure to ambient levels of urban particles affects mouse lung development. Am J Respir Crit Care Med. 2008;178(7):721-728.

6. Shah PS, Balkhair T. Knowledge Synthesis Group on determinants of preterm/LBW births. Air pollution and birth outcomes: a systematic review. Environ Int. 2011;37(2):498-516.

7. Dadvand P, Parker J, Bell ML, et al. Maternal exposure to particulate air pollution and term birth weight: a multi-country evaluation of effect and heterogeneity. Environ Health Perspect. 2013;121(3):267-373.

8. Zhu X, Liu Y, Chen Y, Yao C, Che Z, Cao J. Maternal exposure to fine particulate matter (PM2.5) and pregnancy outcomes: a meta-analysis. Environ Sci Pollut Res Int. 2015;22(5):3383-3396.

9. Pedersen M, Giorgis-Allemand L, Bernard C, et al. Ambient air pollution and low birthweight: a European cohort study (ESCAPE). Lancet Respir Med. 2013;1(9):695-704.

10. Sapkota A, Chelikowsky, Nachman DE, Cohen AJ, Ritz B. Exposure to particulate matter and adverse birth outcomes: a comprehensive review and meta-analysis. Air Qual Atmos Health. 2012;5:369-381.

11. Llop S, Ballester F, Estarlich M, et al. Social factors associated with nitrogen dioxide $\left(\mathrm{NO}_{2}\right)$ exposure during pregnancy: the INMA-Valencia project in Spain. Soc Sci Med. 2011;72(6):890-898.

12. Gehring U, Casas M, Brunekreef B, et al. Environmental exposure assessment in European birth cohorts: results from the ENRIECO project. Environ Health. 2013;12:8.

13. Guarnieri M, Balmes JR. Outdoor air pollution and asthma. Lancet. 2014;383(9928):1581-1592.

14. van den Hooven EH, Pierik FH, de Kluizenaar Y, et al. Air pollution exposure during pregnancy, ultrasound measures of fetal growth, and adverse birth outcomes: a prospective cohort study. Environ Health Perspect. 2012;120(1):150-156.

15. Gehring U, Wijga AH, Fischer P, et al. Traffic-related air pollution, preterm birth and term birth weight in the PIAMA birth cohort study. Environ Res. 2011;111(1):125-135.

16. Estarlich M, Ballester F, Aguilera I, et al. Residential exposure to outdoor air pollution during pregnancy and anthropometric measures at birth in a multicenter cohort in Spain. Environ Health Perspect. 2011; 119(9):1333-1338.

17. Iñiguez C, Ballester F, Estarlich M, et al. Prenatal exposure to trafficrelated air pollution and fetal growth in a cohort of pregnant women. Occup Environ Med. 2012;69(10):736-744.

18. Aguilera I, Garcia-Esteban R, Iñiguez C, et al. Prenatal exposure to traffic-related air pollution and ultrasound measures of fetal growth in the INMA Sabadell cohort. Environ Health Perspect. 2010;118(5): $705-711$.
19. Ballester F, Estarlich M, Iñiguez C, et al. Air pollution exposure during pregnancy and reduced birth size: a prospective birth cohort study in Valencia, Spain. Environ Health. 2010;9:6.

20. Pereira G, Cook AG, Haggar F, Bower C, Nassar N. Locally derived traffic-related air pollution and fetal growth restriction: a retrospective cohort study. Occup Environ Med. 2012;69(11):815-822.

21. Slama R, Thiebaugeorges O, Goua V, et al; EDEN Mother-Child Cohort Study Group. Maternal personal exposure to airborne benzene and intrauterine growth. Environ Health Perspect. 2009;117(8):1313-1321.

22. Ritz B, Qiu J, Lee PC, et al. Prenatal air pollution exposure and ultrasound measures of fetal growth in Los Angeles, California. Environ Res. 2014;130:7-13.

23. Llop S, Ballester F, Estarlich M, Esplugues A, Rebagliato M, Iñiguez C. Preterm birth and exposure to air pollutants during pregnancy. Environ Res. 2010;110(8):778-785.

24. Tang D, Li TY, Chow JC, et al. Air pollution effects on fetal and child development: a cohort comparison in China. Environ Pollut. 2014;185: 90-96.

25. Gehring U, van Eijsden M, Dijkema MB, van der Wal MF, Fischer P, Brunekreef B. Traffic-related air pollution and pregnancy outcomes in the Dutch ABCD birth cohort study. Occup Environ Med. 2011; 68(1):36-43.

26. Pearce MS, Glinianaia SV, Rankin J, et al. No association between ambient particulate matter exposure during pregnancy and stillbirth risk in the north of England, 1962-1992. Environ Res. 2010;110(1):118-122.

27. Pearce MS, Glinianaia SV, Ghosh R, et al. Particulate matter exposure during pregnancy is associated with birth weight, but not gestational age, 1962-1992: a cohort study. Environ Health. 2012;11:13.

28. Hannam K, McNamee R, Baker P, Sibley C, Agius R. Maternal residential proximity to major roads in north west England and adverse pregnancy outcomes. J Occup Environ Med. 2013;55(11):1329-1336.

29. van den Hooven EH, Jaddoe VW, de Kluizenaar Y, et al. Residential traffic exposure and pregnancy-related outcomes: a prospective birth cohort study. Environ Health. 2009;8:59.

30. Vrijheid M, Martinez D, Aguilera I, et al. Socioeconomic status and exposure to multiple environmental pollutants during pregnancy: evidence for environmental inequity? J Epidemiol Community Health. 2012;66(2):106-113.

31. Choi H, Perera FP. Sources of greater fetal vulnerability to airborne polycyclic aromatic hydrocarbons among African Americans. J Epidemiol Community Health. 2012;66(2):121-126.

32. van den Hooven EH, Pierik FH, de Kluizenaar Y, et al. Air pollution exposure and markers of placental growth and function: the generation R study. Environ Health Perspect. 2012;120(12):1753-1759.

33. Kajekar R. Environmental factors and developmental outcomes in the lung. Pharmacol Ther. 2007;114(2):129-145.

34. Selgrade MK, Blain RB, Fedak KM, Cawley MA. Potential risk of asthma associated with in utero exposure to xenobiotics. Birth Defects Res C Embryo Today. 2013;99(1):1-13.

35. Harding R, Maritz G. Maternal and fetal origins of lung disease in adulthood. Semin Fetal Neonatal Med. 2012;17(2):67-72.

36. Mölter A, Agius RM, de Vocht F, et al. Long-term exposure to $\mathrm{PM}_{10}$ and $\mathrm{NO}_{2}$ in association with lung volume and airway resistance in the MAAS birth cohort. Environ Health Perspect. 2013;121(10):1232-1238.

37. Schultz ES, Gruzieva O, Bellander T, et al. Traffic-related air pollution and lung function in children at 8 years of age: a birth cohort study. Am J Respir Crit Care Med. 2012;186(12):1286-1291.

38. Gehring U, Gruzieva O, Agius RM, et al. Air pollution exposure and lung function in children: the ESCAPE project. Environ Health Perspect. 2013;121(11-12):1357-1364.

39. Jedrychowski WA, Perera FP, Maugeri U, et al. Effect of prenatal exposure to fine particulate matter on ventilatory lung function of preschool children of non-smoking mothers. Paediatr Perinat Epidemiol. 2010;24(5):492-501.

40. Jedrychowski WA, Perera FP, Maugeri U, et al. Long term effects of prenatal and postnatal airborne PAH exposures on ventilatory lung function of non-asthmatic preadolescent children. Prospective birth cohort study in Krakow. Sci Total Environ. 2015;502:502-509. 
41. Jedrychowski WA, Perera FP, Maugeri U, et al. Intrauterine exposure to polycyclic aromatic hydrocarbons, fine particulate matter and early wheeze. Prospective birth cohort study in 4-year olds. Pediatr Allergy Immunol. 2010;21(4 pt 2):e723-e732.

42. Jedrychowski WA, Perera FP, Majewska R, et al. Separate and joint effects of tranplacental and postnatal inhalatory exposure to polycyclic aromatic hydrocarbons: prospective birth cohort study on wheezing events. Pediatr Pulmonol. 2014;49(2):162-172.

43. Rosa MJ, Jung KH, Perzanowski MS, et al. Prenatal exposure to polycyclic aromatic hydrocarbons, environmental tobacco smoke and asthma. Respir Med. 2011;105(6):869-876.

44. Chiu YH, Coull BA, Sternthal MJ, et al. Effects of community violence and ambient air pollution on childhood wheeze in an urban population. J Allergy Clin Immunol. 2014;133(3):713-722.

45. Patel MM, Quinn JW, Jung KH, et al. Traffic density and stationary sources of air pollution associated with wheeze, asthma, and immunoglobulin E from birth to age 5 years among New York City children. Environ Res. 2011;111(8):1222-1229.

46. Esplugues A, Ballester F, Estarlich M, et al. Outdoor, but not indoor, nitrogen dioxide exposure is associated with persistent cough during the first year of life. Sci Total Environ. 2011;409(22):4667-4673.

47. Fuertes E, Standl M, Cyrys J, et al. A longitudinal analysis of associations between traffic-related air pollution with asthma, allergies and sensitization in the GINIplus and LISAplus birth cohorts. Peer J. 2013;1 e193.

48. Baïz N, Slama R, Béné MC, et al. Maternal exposure to air pollution before and during pregnancy related to changes in newborn's cord blood lymphocyte subpopulations. The EDEN study cohort. BMC Pregnancy Childbirth. 2011;11:87.

49. Latzin P, Frey U, Armann J, et al. Exposure to moderate air pollution during late pregnancy and cord blood cytokine secretion in healthy neonates. PLoS One. 2011;6(8):e23130.

50. Gurley ES, Homaira N, Salje H, et al. Indoor exposure to particulate matter and the incidence of acute lower respiratory infections among children: a birth cohort study in urban Bangladesh. Indoor Air. 2013;23(5):379-386.

51. Stern G, Latzin P, Röösli M, et al. A prospective study of the impact of air pollution on respiratory symptoms and infections in infants. Am J Respir Crit Care Med. 2013;187(12):1341-1348.

52. Vieira SE, Stein RT, Ferraro AA, et al. Urban air pollutants are significant risk factors for asthma and pneumonia in children: the influence of location on the measurement of pollutants. Arch Bronconeumol. 2012;48(11):389-395.

53. Rice MB, Rifas-Shiman SL, Oken E, et al. Exposure to traffic and early life respiratory infection: a cohort study. Pediat Pulmonol. 2015;50: 252-259.

54. Aguilera I, Pedersen M, Garcia-Esteban R, et al. Early-life exposure to outdoor air pollution and respiratory health, ear infections, and eczema in infants from the INMA study. Environ Health Perspect. 2013;121(3):387-392.
55. Jedrychowski WA, Perera FP, Spengler JD, et al. Intrauterine exposure to fine particulate matter as a risk factor for increased susceptibility to acute broncho-pulmonary infections in early childhood. Int J Hyg Environ Health. 2013;216(4):395-401.

56. Burke H, Leonardi-Bee J, Hashim A, et al. Prenatal and passive smoke exposure and incidence of asthma and wheeze: systematic review and meta-analysis. Pediatrics. 2012;129(4):735-744.

57. Duijts L, Jaddoe VW, van der Valk RJ, et al. Fetal exposure to maternal and paternal smoking and the risk of wheezing in preschool children: The Generation R Study. Chest. 2012;141(4):876-885.

58. Iñiguez C, Ballester F, Amorós R, Murcia M, Plana A, Rebagliato M. Active and passive smoking during pregnancy and ultrasound measures of fetal growth in a cohort of pregnant women. J Epidemiol Community Health. 2012;66(6):563-570.

59. Desrosiers C, Boucher O, Forget-Dubois N, et al. Associations between prenatal cigarette smoke exposure and externalized behaviors at school age among Inuit children exposed to environmental contaminants. Neurotoxicol Teratol. 2013;39:84-90.

60. Rückinger S, Rzehak P, Chen CM, et al; GINI-plus Study Group. Prenatal and postnatal tobacco exposure and behavioral problems in 10-year-old children: results from the GINI-plus prospective birth cohort study. Environ Health Perspect. 2010;118(1):150-154.

61. Newman RB, Momirova V, Dombrowski MP, et al; Eunice Kennedy Shriver National Institute of Child Health and Human Development Maternal-Fetal Medicine Units (MFMU) Network. The effect of active and passive household cigarette smoke exposure on pregnant women with asthma. Chest. 2010;137(3):601-608.

62. Carlsten C, Dimich-Ward H, DyBuncio A, Becker AB, Chan-Yeung M. Cotinine versus questionnaire: early-life environmental tobacco smoke exposure and incident asthma. BMC Pediatr. 2012;12:187.

63. Prabhu N, Smith N, Campbell D, et al. First trimester maternal tobacco smoking habits and fetal growth. Thorax. 2010;65(3):235-240.

64. Thacher JD, Gruzieva O, Pershagen G, et al. Pre- and postnatal exposure to parental smoking and allergic disease through adolescence. Pediatrics. 2014;134(3):428-434.

65. Sunyer J, Garcia-Esteban R, Castilla AM, et al; INMA Project. INMA project. Exposure to second-hand smoke and reproductive outcomes depending on maternal asthma. Eur Respir J. 2012;40(2):371-376.

66. Robison RG, Kumar R, Arguelles LM, et al. Maternal smoking during pregnancy, prematurity and recurrent wheezing in early childhood. Pediatr Pulmonol. 2012;47(7):666-673.

67. Ruskamp J, Smit H, Rovers M, et al. Neonatal total IgE and respiratory tract infections in children with intrauterine smoke exposure. Arch Dis Child. 2010;95(6):427-431.
International Journal of COPD

\section{Publish your work in this journal}

The International Journal of COPD is an international, peer-reviewed journal of therapeutics and pharmacology focusing on concise rapid reporting of clinical studies and reviews in COPD. Special focus is given to the pathophysiological processes underlying the disease, intervention programs, patient focused education, and self management protocols.

\section{Dovepress}

This journal is indexed on PubMed Central, MedLine and CAS. The manuscript management system is completely online and includes a very quick and fair peer-review system, which is all easy to use. Visit http://www.dovepress.com/testimonials.php to read real quotes from published authors. 